\title{
Pharmacokinetics of intravenous telavancin in healthy subjects with varying degrees of renal impairment
}

\author{
Philip D. Worboys $^{1} \cdot$ Shekman L. Wong ${ }^{2} \cdot$ Steven L. Barriere $^{1}$
}

Received: 10 November 2014 / Accepted: 7 April 2015 / Published online: 5 May 2015

(C) The Author(s) 2015. This article is published with open access at Springerlink.com

\begin{abstract}
Purpose We evaluated the effect of renal impairment (RI) on the pharmacokinetics of telavancin and hydroxypropylbetadex (excipient in the telavancin drug product).

Methods Adults with normal, mild, moderate or severe RI or end-stage renal disease (ESRD) receiving haemodialysis were included in two open-label, phase I studies of single-dose telavancin at $7.5 \mathrm{mg} / \mathrm{kg}$ (study A, $n=29$ ) or $10 \mathrm{mg} / \mathrm{kg}$ (study $\mathrm{B}, n=43)$. Pharmacokinetic analysis of telavancin and hydroxypropylbetadex plasma concentration versus time was performed in these subjects.

Results The results in studies A and B were similar: telavancin systemic exposure (area under the concentrationtime curve from 0 to infinity $\left[\mathrm{AUC}_{0-\infty}\right]$ ) increased with RI. Telavancin half-life $(h$, mean \pm SD) increased in subjects with severe RI compared with subjects with normal renal function from $6.9 \pm 0.6$ in study A and $6.5 \pm 0.9$ in study B to $14.5 \pm 1.3$ and $11.8 \pm 6.7$, respectively. Conversely, clearance $(\mathrm{ml} / \mathrm{h} / \mathrm{kg}$, mean $\pm \mathrm{SD}$ ) decreased in subjects with severe RI compared with subjects with normal renal function from $13.7 \pm 2.1$ in study A and $17.0 \pm 3.2$ in study B to $6.18 \pm 0.63$ and $6.5 \pm 1.5$,
\end{abstract}

Clinical trial registry number These trials are phase 1 clinical investigations and thus do not meet the FDAAA 801 definition of an "applicable clinical trial" requiring registration.

Philip D. Worboys

pworboys@theravance.com

1 Theravance Biopharma US, Inc., 901 Gateway Boulevard, South San Francisco, CA 94080, USA

2 AbbVie Biotherapeutics Corp., Redwood City, CA 94063, USA respectively. Systemic exposures for hydroxypropylbetadex also increased with severity of RI.

Conclusions Results from two independent phase 1 studies suggest that dose adjustment of telavancin is required in subjects with varying degrees of RI.

Keywords Telavancin $\cdot$ Lipoglycopeptide $\cdot$ Renal impairment $\cdot$ Pharmacokinetics $\cdot$ Hydroxypropylbetadex

\section{Introduction}

Antibiotic resistance among Gram-positive bacteria, including staphylococci, has necessitated the development of new antibiotics. Vancomycin, a glycopeptide antibiotic, has been the drug of choice to treat methicillin-resistant Staphylococcus aureus infections. The increasing prevalence of multidrugresistant strains, including those that are resistant to vancomycin, has resulted in the development of the lipoglycopeptide class of antibiotics, which have a lipophilic side chain linked to a glycopeptide backbone. Members of this class of antibiotics include oritavancin, dalbavancin and telavancin.

Telavancin is a bactericidal lipoglycopeptide antibiotic with activity against clinically relevant Gram-positive bacteria [1]. The antimicrobial activity of telavancin results from a dual mode of action, including inhibition of peptidoglycan synthesis and disruption of the functional integrity of the bacterial membrane $[2,3]$. In the USA and Canada, intravenous (i.v.) telavancin is approved for the treatment of adult patients with complicated skin and skin structure infections caused by susceptible Gram-positive bacteria [4, 5]. In Europe, telavancin is approved for the treatment of nosocomial pneumonia, including ventilator-associated pneumonia, known or suspected to be caused by methicillin-resistant $S$. aureus when other alternatives are unsuitable [6], and for the treatment of hospital- 
acquired bacterial pneumonia and ventilator-associated bacterial pneumonia due to $S$. aureus when other alternatives are not suitable in the USA [5]. In healthy adult volunteers, telavancin at $7.5-15 \mathrm{mg} / \mathrm{kg} /$ day administered as an i.v. infusion displayed linear pharmacokinetics, with an elimination half-life $\left(t_{1 / 2}\right)$ averaging $7 \mathrm{~h}$ and trough plasma concentrations exceeding the minimum concentration required to inhibit the growth of $90 \%$ of organisms for key Gram-positive pathogens $[7,8]$. Following i.v. administration, telavancin is largely excreted intact in urine ( $82 \%$ after a single administration of $10 \mathrm{mg} / \mathrm{kg}$ ) [9], and no significant gender- or age-related differences in telavancin pharmacokinetics have been observed in healthy volunteers $[8,10]$. Co-administration of telavancin with the renally excreted antibiotics aztreonam or piperacillin/ tazobactam had no significant effect on the pharmacokinetics of any of the drugs [11]. The pharmacokinetic profile supports a once-daily dosage strategy for telavancin in patients with normal renal function.

It was expected that systemic exposure to telavancin would be greater in patients with reduced creatinine clearance $\left(\mathrm{CL}_{\mathrm{cr}}\right)$ than in those with normal $\mathrm{CL}_{\mathrm{cr}}$. In order to develop dosage recommendations, we examined the pharmacokinetic profile of telavancin and the drug product excipient hydroxypropylbetadex, used in telavancin's formulation to aid solubilisation, in subjects with various degrees of renal impairment in two phase 1 trials, Studies 103a (Theravance, Inc.) and 2403 (Astellas Pharma Europe B.V.), herein referred to as study A and study B, respectively.

\section{Materials and methods}

\section{Study designs}

Study A was a phase 1, open-label, single-arm, single-dose, two-centre study (Quintiles Limited, Guy's Drug Research Centre, London, UK and MDS Pharma Services, New Orleans, LA, USA) that examined the effects of renal impairment on telavancin pharmacokinetics in subjects with varying degrees of renal impairment. Study B was a phase 1, openlabel, single-dose, three-centre study in Poland (SP ZOZ Szpital Praski, Warsaw; SP Specjalistyczny Szpital, Zachodni, Grodzisk Mazowiecki; and SZP ZOZ, Wołominie, Wołomin) that investigated the effect of mild, moderate and severe renal impairment on the pharmacokinetics of telavancin compared with subjects with normal renal function.

\section{Ethics}

The study protocols were approved by the institutional review board at each participating site, and both studies were conducted in full compliance with the principles of the International Conference on Harmonization of Technical Requirements for Registration of Pharmaceuticals for Human Use,
Good Clinical Practice and the Declaration of Helsinki. Written informed consent was obtained from all subjects.

\section{Subjects}

Subjects included men and non-pregnant women and, in study A or B, respectively, were $\geq 18$ years or $20-79$ years of age with a body mass index of $18-36$ or $18.5-34 \mathrm{~kg} / \mathrm{m}^{2}$. Subjects were either healthy or had mild, moderate or severe renal impairment. Subjects were excluded if they had a history of any relevant pulmonary, haematologic, hepatic, immunologic, endocrine, metabolic, rheumatic, neurologic or psychiatric disorder. Subjects with stable, adequately treated medical conditions could be enrolled provided that their medical regimen was unchanged in the 3 months before study participation and that participation did not place them at increased risk of adverse events.

Subjects were assigned to the renal impairment strata based on assessment during pre-study screening. For study A, strata assignment was based on $\mathrm{CL}_{\mathrm{cr}}$ calculated using the CockcroftGault (C-G) equation [12] (Table 1). For study B, assignment was based on the estimated glomerular filtration rate (eGFR) using the Modification of Diet in Renal Disease formula [13] (Table 1). Summary statistics for Study B were also prepared using the $\mathrm{C}-\mathrm{G}$ equation [12] with and without normalization to body surface area. Creatinine assays were performed at each clinical site using UV absorbance assays at $512 \mathrm{~nm}$ to detect the yellow-red complex formed from the reaction of creatinine and picric acid under alkaline conditions.

In subjects with end-stage renal disease (ESRD), haemodialysis was initiated 2-4 h after study drug administration (study A only). Haemodialysis sessions were $4 \mathrm{~h}$ in duration, and when possible, a similar type of dialyzer at a similar blood flow rate was used across haemodialysis subjects.

Table 1 Determination of renal function by estimated pre-dose creatinine clearance and glomerular filtration rate values

\begin{tabular}{lll}
\hline $\begin{array}{l}\text { Renal impairment } \\
\text { group }\end{array}$ & $\begin{array}{l}\text { Study A, } \\
\mathrm{CL}_{\mathrm{cr}}(\mathrm{mL} / \mathrm{min})^{\mathrm{a}}\end{array}$ & $\begin{array}{l}\text { Study B, eGFR } \\
\left(\mathrm{mL} / \mathrm{min} / 1.73 \mathrm{~m}^{2}\right)^{\mathrm{b}}\end{array}$ \\
\hline $\begin{array}{l}\text { Normal } \\
\text { Mild }\end{array}$ & $>80$ & $\geq 90$ \\
Moderate & $51-80$ & 60 to 89 \\
$\begin{array}{l}\text { Severe } \\
\text { ESRD }\end{array}$ & $30-50$ & 30 to 59 \\
& $<30$ & 15 to 29 \\
& $\begin{array}{c}\text { Subjects maintained } \\
\text { on dialysis }\end{array}$ & NA \\
\hline
\end{tabular}

$E S R D$ end-stage renal disease, $C L_{c r}$ creatinine clearance, $e G F R$ estimated glomerular filtration rate, $N A$ not applicable

${ }^{\text {a }}$ Cockcroft-Gault equation

${ }^{\mathrm{b}}$ Modification of Diet in Renal Disease formula 


\section{Treatments}

Telavancin for injection was supplied as a sterile, lyophilized powder for i.v. injection. Each millilitre of formulated solution contained approximately $10 \mathrm{mg}$ of telavancin, $100 \mathrm{mg}$ of hydroxypropylbetadex (to improve solubility) and $12.5 \mathrm{mg}$ mannitol as excipients. In study A, subjects with renal impairment received a single, $1-\mathrm{h}$ infusion of telavancin $7.5 \mathrm{mg} / \mathrm{kg}$ on day 1 . In study $B$, subjects received a single, 1 -h infusion of telavancin $10 \mathrm{mg} / \mathrm{kg}$ on day 1 . In study $\mathrm{B}$, the actual dose of telavancin administered was approximately $10 \%$ less than planned due to a residual amount of solution remaining within the infusion system.

\section{Pharmacokinetic assessments_-sample collection}

Plasma Blood samples $(5-6 \mathrm{ml})$ were collected in sodium heparin glass tubes and stored chilled until the plasma was harvested by centrifugation and stored at approximately $-70{ }^{\circ} \mathrm{C}$ or below until transferred frozen to a central laboratory for analysis. For subjects with varying degrees of renal impairment, samples were collected in study A pre-infusion, at 1 , $2,4,6,8,12,24,36$ and $48 \mathrm{~h}$ after the start of infusion for all groups and also at 72 and $96 \mathrm{~h}$ post-infusion for subjects with severe renal impairment or ESRD. In study $\mathrm{B}$, samples were collected pre-infusion and at $0.5,1,1.5,2,3,4,6,8,10,12$, $16,24,36,48,60,72,84$ and 96 h post-dose.

Urine Because the urine assay for telavancin was not optimized at the time of study $\mathrm{A}$, no results were reported; the assays were subsequently conducted in study B, where samples were collected pre-infusion and at 0-6, 6-12, 12-24, 24 $36,36-48,48-60,60-72,72-84$ and $84-96 \mathrm{~h}$ after the start of infusion. Aliquots were collected and stored at $-70{ }^{\circ} \mathrm{C}$ or lower.

ESRD For subjects with ESRD (study A), a sample from the inflow to the dialyzer on the arterial side was collected before dialysis and at 1, 2, 3 and $4 \mathrm{~h}$ after the start of dialysis; dialysate fluid samples $(10 \mathrm{ml})$ were collected before and at 30 min intervals during dialysis. Plasma samples were also collected at $0,60,120,180$ and 240 min following the start of dialysis.

\section{Analytical methods}

In study A, plasma samples were analysed at a central laboratory (Covance Central Laboratory Services, Indianapolis, IN, USA) using a validated liquid chromatography-mass spectrometry (LC-MS) method for telavancin, which has been previously described [6]. The method was linear over the range $0.25-100 \mu \mathrm{g} / \mathrm{ml}$ and the lower limit of quantification (LLQ) was $0.25 \mu \mathrm{g} / \mathrm{ml}$. Dialysate samples from study A were analysed at a separate central laboratory (Covance Laboratories, Madison, WI, USA) using a similar validated LC-MS method. The method was linear over the range of $0.1-$ $25.0 \mu \mathrm{g} / \mathrm{ml}$, and the LLQ in human dialysate for telavancin was $0.1 \mu \mathrm{g} / \mathrm{ml}$. Study samples outside the calibration range were diluted and re-assayed. Dilution QC samples were included in batches where samples were diluted prior to analysis. The inter-day precision and accuracy of quality controls and standards during the validation was better than $13 \%$ for all concentrations evaluated. Plasma concentrations of hydroxypropylbetadex were determined at Theravance, Inc. (South San Francisco, CA, USA) using high-performance LC (HPLC) with fluorescence analysis. Solid-phase extraction was used for sample preparation, after which hydroxypropylbetadex was complexed with a mobile phase additive (1-napthol). The resulting hydroxypropylbetadex sample peaks were then quantified against external standards. The standard curve range for hydroxypropylbetadex was 10$800 \mu \mathrm{g} / \mathrm{ml}$, with an LLQ of $10 \mu \mathrm{g} / \mathrm{ml}$.

In study B, plasma and urine concentrations of telavancin were analysed at Pharmaceutical Product Development (Richmond, VA, USA) after receipt of all samples using a validated LC-MS/MS method. The method was linear over the range $0.1-25 \mu \mathrm{g} / \mathrm{ml}$ for telavancin in plasma (LLQ $0.1 \mu \mathrm{g} / \mathrm{ml}$ ) and $0.25-80 \mu \mathrm{g} / \mathrm{ml}$ (LLQ $0.25 \mu \mathrm{g} / \mathrm{ml}$ ) for telavancin in urine. The inter- and intra-assay precision and accuracy of quality controls and standards during the validation was within $7.6 \%$ in plasma and $10.2 \%$ in urine. Plasma concentrations of hydroxypropylbetadex were determined at Pharmaceutical Research Associates (Assen, The Netherlands) by a validated HPLC fluorescence method.

\section{Pharmacokinetic analyses}

Pharmacokinetic parameters of telavancin were determined by non-compartmental analysis using WinNonlin version 4.0.1 (study A) and version 5.3 (study B) (Pharsight, Mountain View, CA, USA); SAS version 9.1.3 (SAS Institute, Cary, $\mathrm{NC}$, USA) was used to analyse the urine pharmacokinetic parameters in study B. Only samples with measureable concentrations were used for the purpose of calculating the pharmacokinetic parameters in both studies. Plasma pharmacokinetic parameters were calculated as previously described [7]. The CL reported for ESRD is the CL for the subjects (i.e., includes residual clearance and any dialysis clearance).

Clearance of telavancin by haemodialysis $\left(\mathrm{CL}_{\mathrm{HD}}\right)$ was calculated as $\mathrm{CL}_{\mathrm{HD}}=\mathrm{Q}_{\mathrm{D}} \times\left(\mathrm{C}_{\mathrm{TLV}}-\mathrm{D}_{\mathrm{TLV}}\right) \div\left(C_{\mathrm{TLV}}\right)$, where $Q_{\mathrm{D}}$ was the dialysate flow rate, $D_{\mathrm{TLV}}$ was the telavancin concentration in the dialysate effluent and $C_{\mathrm{TLV}}$ was the telavancin concentration in the arterial blood entering the dialyzer. Dialyzers used included the PSN 210 and the $2 \mathrm{~K} 2.5$ Dialysate (both Gambro). The dialysate flow rate was $800 \mathrm{~mL} / \mathrm{min}$, and blood flow rates in patients ranged from 300 to $500 \mathrm{~mL} / \mathrm{min}$. 
Also, in study A, the cumulative amount of telavancin estimated in dialysis fluid was determined by multiplying the telavancin concentration in aliquots collected at 30-min intervals by the dialysate volume per collection period and then summing the individual hourly excretion amounts. In study B, the percentage of the dose excreted in urine was calculated as $\mathrm{Ae}_{0-t} \%=\mathrm{Ae}_{0-t} / \mathrm{dose} \times 100 \%$ and $\mathrm{Ae}_{0-\infty} \%=\mathrm{Ae}_{0-\infty} / \mathrm{dose} \times$ $100 \%$. Renal $\mathrm{CL}\left(\mathrm{CL}_{\mathrm{R}}\right)$ was calculated as $\mathrm{CL}_{\mathrm{R}}=\mathrm{Ae} \div$ AUC, with Ae and AUC both taken over the same interval and where Ae is amount of telavancin excreted over time, and AUC is area under the concentration-time curve.

\section{Protein binding assay}

Protein binding was assayed in study A. The plasma protein binding of telavancin $50 \mu \mathrm{g} / \mathrm{ml}$ (spiked with $1 \mu \mathrm{g} / \mathrm{ml}$ of $\left[{ }^{14} \mathrm{C}\right.$ ] telavancin [Vitrax, Placentia, CA, USA]) was determined in vitro by analysing pre-infusion plasma samples under equilibrium dialysis. The percent of protein binding was calculated as follows:

$\%$ bound $=($ donor-receptor $) \div($ donor $) \times 100 \%$, and

$\%$ unbound $=$ receptor $\div($ donor $) \times 100 \%$,

where donor $=$ plasma side concentration and receptor $=$ buffer side concentration.

\section{Statistical analyses}

Summary statistics were calculated for pharmacokinetic parameters by renal impairment group in both studies.

Concentration values within treatment and time point were evaluated for outliers using Tukey's inter-quartile range method [14]. Source documentation was reviewed for all identified outliers for supportive evidence that would deem the values unreliable.

All outliers were included in the analyses. For all summaries and analyses, the baseline value was the last assessment taken prior to the administration of the dose of study drug.

\section{Results}

\section{Subjects}

In all, 29 (study A) and 43 (study B) subjects with varying degrees of renal impairment were enrolled. The mean $\mathrm{CL}_{\mathrm{cr}}$ in each group of subjects with renal impairment was within the pre-defined range (Table 1), enabling comparative assessment of telavancin pharmacokinetics with respect to level of renal function. Demographic parameters for each group are presented in Table 2. One subject with mild renal impairment from study A received only a partial dose (approximately two thirds) of telavancin due to a flushing reaction on the upper body. This subject was excluded from pharmacokinetic evaluation but was included in the safety analysis.

\section{Pharmacokinetics}

\section{Telavancin}

For both studies, following a single, 1-hour i.v. infusion of telavancin $7.5 \mathrm{mg} / \mathrm{kg}$ (study A) or $10 \mathrm{mg} / \mathrm{kg}$ (study B), plasma telavancin concentrations declined in an apparent biexponential manner, with a slower decline in subjects with greater degrees of renal impairment (Fig. 1a, b; study A and $\mathrm{B}$, respectively). The distribution of telavancin, as measured by mean maximum concentration and volume at steady state $\left(V_{\mathrm{ss}}\right)$, was similar in healthy subjects and those with varying degrees of renal impairment (Table 3). In subjects with severe renal impairment or ESRD, mean plasma telavancin CL was reduced by more than $50 \%$, and $t_{1 / 2}$ almost doubled in both studies. A strong relationship was found between plasma CL of telavancin and $\mathrm{CL}_{\mathrm{cr}}$ over the entire range of renal function (Fig. 2a): $r^{2}=0.76$ in study A and $r^{2}=0.62$ in study B. Based on comparison of AUC from time zero to infinity $\left(\mathrm{AUC}_{0-\infty}\right)$ estimates in healthy subjects, systemic exposure to telavancin in study A/study B was increased by 13/12, 29/74 and 118/ $160 \%$ in subjects with mild, moderate and severe renal impairment, respectively. The corresponding increase in $\mathrm{AUC}_{0-\infty}$ in the ESRD group in study A was $79 \%$. In subjects who underwent haemodialysis on the same day as administration of $7.5 \mathrm{mg} / \mathrm{kg}$ of telavancin, approximately $6 \%$ of the total administered dose was removed by dialysis session. The dialysis clearance was estimated to be $4.5 \mathrm{ml} / \mathrm{min}$ $(271 \mathrm{ml} / \mathrm{h}$; approximately $25 \%$ of clearance in normal subjects).

Plasma protein binding of telavancin in vitro was determined for all subjects who provided a pre-dose plasma sample in study A only. There were no appreciable differences among renal impairment groups in the degree of telavancin protein binding: the average binding of telavancin to plasma proteins was approximately $87 \%$ in all groups (Table 3).

Urinalysis results from study B (Table 4) show that the excretion of telavancin $\left(\mathrm{Ae}_{0-\mathrm{t}}\right.$, normalized to a telavancin $10 \mathrm{mg} / \mathrm{kg}$ dose) decreased with declining renal function from a mean ( \pm standard deviation) of $436 \pm 91 \mathrm{mg}$ in subjects with normal renal function to $207 \pm 62 \mathrm{mg}$ in subjects with severe renal impairment, corresponding to 62.8 and $28.1 \%$ of the dose, respectively. All other values $\left(\mathrm{Ae}_{0-\infty}, \mathrm{Ae}_{0-\infty} \%\right)$ reflected the same trend. $\mathrm{CL}_{R}$ decreased with renal function from $10.2 \pm$ 1.8 to $1.8 \pm 0.6 \mathrm{ml} / \mathrm{h} / \mathrm{kg}$, becoming significant in subjects with moderate or severe renal impairment $(P<0.0001)$. 
Table 2 Demographics and baseline characteristics of phase I study volunteers by degree of renal impairment

\begin{tabular}{|c|c|c|c|c|c|}
\hline & \multicolumn{5}{|c|}{ Study $\mathrm{A} / \mathrm{B}$, mean \pm standard deviation } \\
\hline & $\begin{array}{l}\text { Normal } \\
(n=6 / 14)\end{array}$ & $\begin{array}{l}\text { Mild } \\
\left(n=7^{\mathrm{a}} / 13\right)\end{array}$ & $\begin{array}{l}\text { Moderate } \\
(n=6 / 8)\end{array}$ & $\begin{array}{l}\text { Severe } \\
(n=4 / 8)\end{array}$ & $\begin{array}{l}\text { ESRD } \\
(n=6 / 0)\end{array}$ \\
\hline Age (years) & $51 \pm 9 / 53 \pm 6$ & $59 \pm 15 / 57 \pm 5$ & $70 \pm 9 / 65 \pm 6$ & $58 \pm 12 / 67 \pm 9$ & $47 \pm 6 / \mathrm{NA}$ \\
\hline Weight (kg) & $79 \pm 10 / 70 \pm 12$ & $76 \pm 15 / 70 \pm 14$ & $69 \pm 11 / 77 \pm 13$ & $80 \pm 17 / 73 \pm 15$ & $81 \pm 23 / / \mathrm{NA}$ \\
\hline Height (cm) & $175 \pm 6 / 164 \pm 7$ & $169 \pm 7 / 165 \pm 13$ & $168 \pm 11 / 162 \pm 8$ & $173 \pm 15 / 163 \pm 6$ & $172 \pm 7 / \mathrm{NA}$ \\
\hline BMI $\left(\mathrm{kg} / \mathrm{m}^{2}\right)$ & $26 \pm 2 / 26 \pm 3$ & $26 \pm 4 / 25 \pm 3$ & $25 \pm 4 / 29 \pm 4$ & $27 \pm 2 / 28 \pm 5$ & $27 \pm 7 / \mathrm{NA}$ \\
\hline $\begin{array}{l}\mathrm{CL}_{\mathrm{cr}}(\mathrm{mL} / \mathrm{min}) / \\
\text { eGFR }\left(\mathrm{mL} / \mathrm{min} / 1.73 \mathrm{~m}^{2}\right)^{\mathrm{b}}\end{array}$ & $94 \pm 11 / 110 \pm 20$ & $67 \pm 9 / 81 \pm 6$ & $40 \pm 7 / 48 \pm 7.5$ & $22 \pm 7 / 21 \pm 5$ & $10 \pm 4 / \mathrm{NA}$ \\
\hline
\end{tabular}

$B M I$ body mass index, $C L_{c r}$ creatinine clearance, $E S R D$ end-stage renal disease, $N A$ not applicable, $S D$ standard deviation

${ }^{a}$ One subject was excluded from pharmacokinetic evaluation due to receipt of an incomplete dose of telavancin but was included in the safety/ demographic population

${ }^{\mathrm{b}}$ See Table 1 for definitions of $\mathrm{CL}_{\mathrm{cr}}(\mathrm{mL} / \mathrm{min})$ from study A and eGFR $\left(\mathrm{mL} / \mathrm{min} / 1.73 \mathrm{~m}^{2}\right)$ from study B

\section{Hydroxypropylbetadex}

In each renal impairment group, the concentration of hydroxypropylbetadex decreased over time in a log-linear manner, indicating first-order disposition processes (Fig. 1c, d; study $\mathrm{A}$ and $\mathrm{B}$, respectively). The $\mathrm{CL}$ decreased with declining renal function (Table 3), and a linear relationship was found between plasma clearance of hydroxypropylbetadex and $\mathrm{CL}_{\mathrm{cr}}$ (Fig. 2b). Plasma clearance of hydroxypropylbetadex was progressively lower in the groups of subjects with increasing degrees of renal impairment and decreased by up to $88 \%$ in study A subjects with ESRD ( $84 \%$ in study B). Thus, after a single, 1-hour i.v. infusion, plasma levels of hydroxypropylbetadex remained measurable for the longest period in the groups with the poorest kidney function: hydroxypropylbetadex $t_{1 / 2}$ was about three (study A) to six (study B) times as high in subjects with severe renal impairment and 12-fold higher in those with ESRD (study A only) relative to those with normal renal function (Table 3).

A plot of total body $\mathrm{CL}$ versus $\mathrm{CL}_{\mathrm{cr}}$ shows an excellent correlation between the two parameters, with complete overlap of the results of the two studies: telavancin (Fig. 2a) and hydroxypropylbetadex (Fig. 2b).

Table 3 Mean ( \pm standard deviation) non-compartmental pharmacokinetic parameters of telavancin and the excipient hydroxypropylbetadex in subjects with varying degrees of renal function (see Table 1 for definitions $\mathrm{CL}_{\mathrm{cr}}\left(\mathrm{ml} / \mathrm{min}\right.$ ) from study $\mathrm{A}$ and eGFR (ml/min/1.73 $\mathrm{m}^{2}$ ) from study B)

\begin{tabular}{|c|c|c|c|c|c|}
\hline \multirow[t]{2}{*}{ Parameter } & \multicolumn{5}{|c|}{ Study A/study B, mean \pm standard deviation } \\
\hline & Normal $(n=6 / 14)$ & Mild $(n=6 / 13)$ & Moderate $(n=6 / 8)$ & Severe $(n=4 / 8)$ & $\operatorname{ESRD}^{\mathrm{a}}(n=6 / 0)$ \\
\hline \multicolumn{6}{|l|}{ Telavancin } \\
\hline Protein binding $(\%)^{\mathrm{a}}$ & $86.5 \pm 1.3$ & $87.5 \pm 1.0$ & $87.8 \pm 1.1$ & $86.7 \pm 1.2$ & $87.6 \pm 1.0 / 0$ \\
\hline$t_{1 / 2}(\mathrm{~h})$ & $6.9 \pm 0.6 / 6.5 \pm 0.9$ & $9.6 \pm 2.9 / 7.8 \pm 2.0$ & $10.6 \pm 2.4 / 8.1 \pm 1.5$ & $14.5 \pm 1.3 / 11.8 \pm 6.7$ & $11.8 \pm 2.8 / 0$ \\
\hline$C_{\max }(\mu \mathrm{g} / \mathrm{mL})$ & $70.6 \pm 11.2 / 76.7 \pm 8.6$ & $65.9 \pm 2.7 / 74.2 \pm 7.3$ & $65.8 \pm 12.1 / 78.0 \pm 4.5$ & $71.8 \pm 7.1 / 83.2 \pm 13.1$ & $52.1 \pm 10.1 / 0$ \\
\hline $\mathrm{AUC}_{0-\infty}(\mu \mathrm{g} \mathrm{h} / \mathrm{mL})$ & $560 \pm 93 / 539 \pm 99$ & $633 \pm 101 / 606 \pm 139$ & $721 \pm 200 / 936 \pm 182$ & $1220 \pm 120 / 1397 \pm 297$ & $1010 \pm 341 / 0$ \\
\hline $\mathrm{CL}(\mathrm{mL} / \mathrm{h} / \mathrm{kg})$ & $13.7 \pm 2.1 / 17.0 \pm 3.2$ & $12.1 \pm 1.9 / 15.2 \pm 4.6$ & $11.1 \pm 3.3 / 9.5 \pm 2.0$ & $6.18 \pm 0.63 / 6.5 \pm 1.5$ & $8.18 \pm 2.65 / 0$ \\
\hline$V_{\mathrm{ss}}(\mathrm{mL} / \mathrm{kg})$ & $131 \pm 16 / 155.4 \pm 30.2$ & $157 \pm 19 / 159.5 \pm 34.5$ & $156 \pm 24 / 157.8 \pm 41.7$ & $136 \pm 10 / 141.9 \pm 17.7$ & $157 \pm 27 / 0$ \\
\hline \multicolumn{6}{|l|}{ Hydroxypropylbetadex } \\
\hline$t_{1 / 2}(\mathrm{~h})$ & $3.02 \pm 1.56 / 2.15 \pm 0.35$ & $4.96 \pm 6.22 / 2.47 \pm 0.55$ & $4.18 \pm 1.27 / 5.09 \pm 2.07$ & $9.84 \pm 3.62 / 12.2 \pm 2.8$ & $37.2 \pm 8.72 / 0$ \\
\hline$C_{\max }(\mu \mathrm{g} / \mathrm{mL})$ & $344 \pm 61 / 386 \pm 51$ & $476 \pm 83 / 367 \pm 37$ & $565 \pm 172 / 453 \pm 58$ & $517 \pm 36 / 479 \pm 57$ & $290 \pm 59 / 0$ \\
\hline $\operatorname{AUC}_{0-\infty}(\mu \mathrm{g} \mathrm{h} / \mathrm{mL})$ & $946 \pm 45 / 971 \pm 199$ & $1880 \pm 1050 / 1083 \pm 275$ & $2720 \pm 1190 / 2512 \pm 921$ & $5440 \pm 1460 / 6385 \pm 1713$ & $8510 \pm 2470 / 0$ \\
\hline $\mathrm{CL}(\mathrm{mL} / \mathrm{h} / \mathrm{kg})$ & $79.5 \pm 3.8 / 94.5 \pm 19.0$ & $49.2 \pm 22.7 / 85.1 \pm 25.3$ & $32.5 \pm 14.2 / 37.2 \pm 11.0$ & $14.5 \pm 3.3 / 14.6 \pm 4.5$ & $9.8 \pm 4.3 / 0$ \\
\hline$V_{\mathrm{ss}}(\mathrm{mL} / \mathrm{kg})$ & $263 \pm 101 / 277.7 \pm 148.2$ & $182 \pm 51 / 248.6 \pm 61.8$ & $160 \pm 71 / 228.2 \pm 56.1$ & $183 \pm 23 / 227.8 \pm 32.7$ & $473 \pm 70 / 0$ \\
\hline
\end{tabular}

The CL reported for ESRD is the CL for the subjects (i.e., includes residual clearance and any dialysis clearance)

$A U C$ area under concentration-time curve, ESRD end-stage renal disease, $C_{\max }$ maximum plasma concentration, $C L$ clearance, $C L_{c r}$ creatinine clearance, $t_{1 / 2}$ terminal elimination half-life, $V_{S S}$ apparent volume of distribution at steady state

${ }^{\mathrm{a}}$ Study A only 

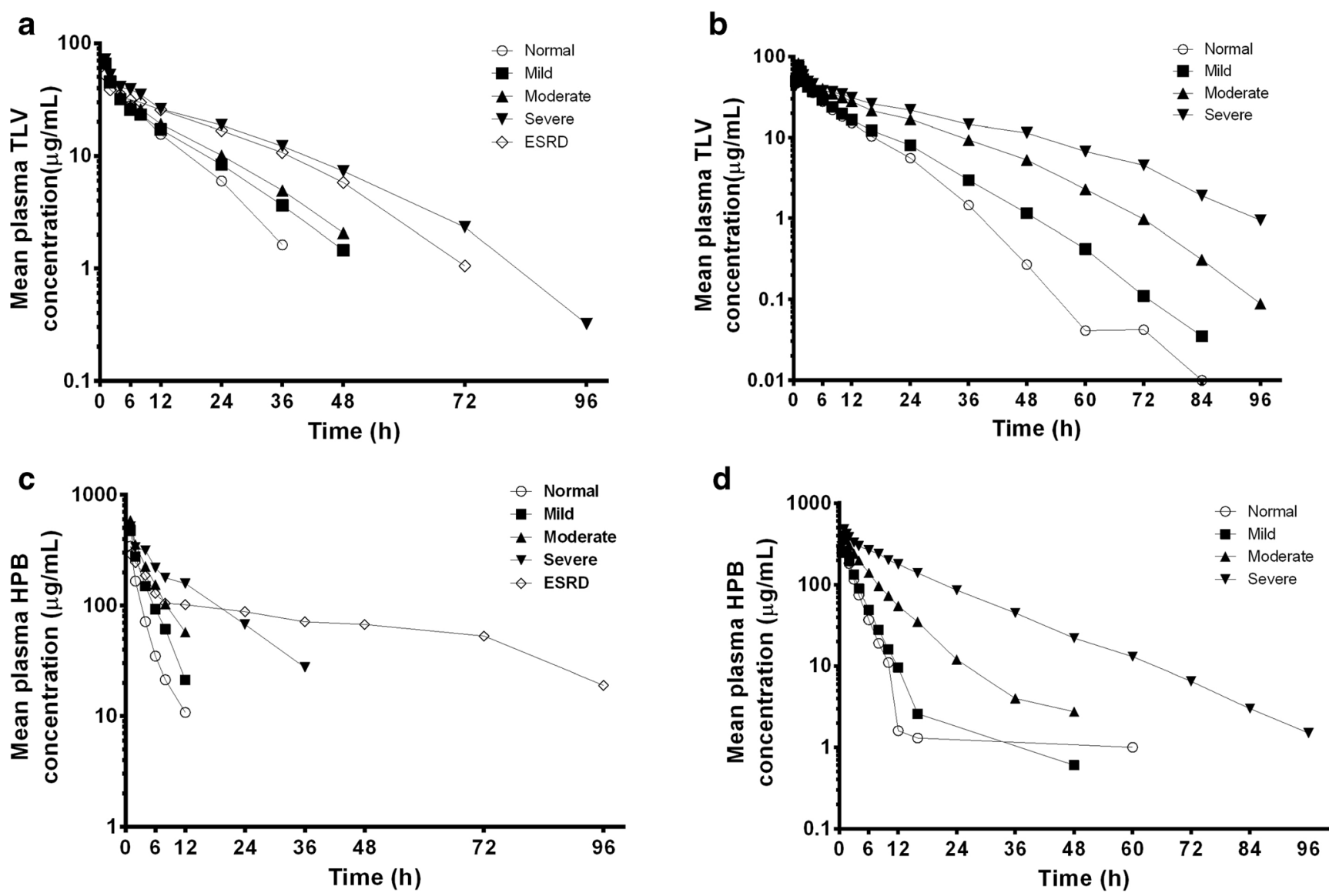

Fig. 1 Mean plasma telavancin $(T L V ; \mathbf{a}, \mathbf{b})$ and hydroxypropylbetadex $(H P B ; \mathbf{c}, \mathbf{d})$ concentration-time profiles in subjects from studies A and $\mathrm{B}$, respectively, with normal renal function and those with mild impairment, moderate impairment, severe impairment, or end-stage renal disease (ESRD)

Table 4 Summary statistics of renal-related urinary pharmacokinetic parameters by renal function category (study B)

\begin{tabular}{|c|c|c|c|c|}
\hline \multirow[t]{2}{*}{ Parameter } & \multicolumn{4}{|c|}{ Mean \pm standard deviation } \\
\hline & Normal renal function & Mild renal impairment & Moderate renal impairment & Severe renal impairment \\
\hline \multicolumn{5}{|l|}{ Telavancin } \\
\hline $\mathrm{Ae}_{0-\mathrm{t}}(\mathrm{mg})^{\mathrm{a}}$ & $436 \pm 91$ & $397 \pm 100$ & $368 \pm 91$ & $207 \pm 62$ \\
\hline $\mathrm{Ae}_{0-\mathrm{t}} \%(\%)$ & $62.8 \pm 9.0$ & $58.2 \pm 11.5$ & $48.4 \pm 8.7$ & $28.0 \pm 4.3$ \\
\hline $\mathrm{Ae}_{0-\infty}(\mathrm{mg})^{\mathrm{a}}$ & $435 \pm 91$ & $396 \pm 100$ & $375 \pm 96$ & $208 \pm 60$ \\
\hline $\mathrm{Ae}_{0-\infty} \%(\%)$ & $62.7 \pm 9.1$ & $58.2 \pm 11.6$ & $48.4 \pm 9.3$ & $28.2 \pm 3.9$ \\
\hline $\mathrm{CL}_{\mathrm{R}}(\mathrm{mL} / \mathrm{h} / \mathrm{kg})$ & $10.5 \pm 1.9$ & $8.8 \pm 3.3$ & $4.7 \pm 1.6$ & $1.9 \pm 0.7$ \\
\hline \multicolumn{5}{|l|}{ Hydroxypropylbetadex } \\
\hline $\mathrm{Ae}_{0-\mathrm{t}}, 10 \mathrm{mg}(\mathrm{mg})^{\mathrm{a}}$ & $4801 \pm 1390$ & $4292 \pm 1449$ & $5190 \pm 709$ & $4879 \pm 1112$ \\
\hline $\mathrm{Ae}_{0-\mathrm{t}} \%(\%)$ & $68.8 \pm 15.9$ & $63.6 \pm 20.5$ & $69.0 \pm 8.6$ & $65.7 \pm 11.4$ \\
\hline $\mathrm{Ae}_{0-\infty}(\mathrm{mg})^{\mathrm{a}}$ & $4786 \pm 1487$ & $4274 \pm 1470$ & $5257 \pm 773$ & $4969 \pm 1070$ \\
\hline $\mathrm{Ae}_{0-\infty}(\%)$ & $68.5 \pm 17.5$ & $63.4 \pm 21.1$ & $68.7 \pm 9.3$ & $67.1 \pm 12.0$ \\
\hline $\mathrm{CL}_{\mathrm{R}}(\mathrm{mL} / \mathrm{h} / \mathrm{kg})$ & $62.9 \pm 15.4$ & $51.4 \pm 19.4$ & $26.5 \pm 7.6$ & $10.0 \pm 4.1$ \\
\hline
\end{tabular}

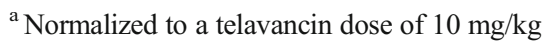

$A e_{0-t}$ amount of telavancin excreted in the urine up to the last quantifiable sample, $A e_{0-\infty}$ amount of telavancin excreted in the urine extrapolated to infinity, $C L_{R}$ renal clearance 

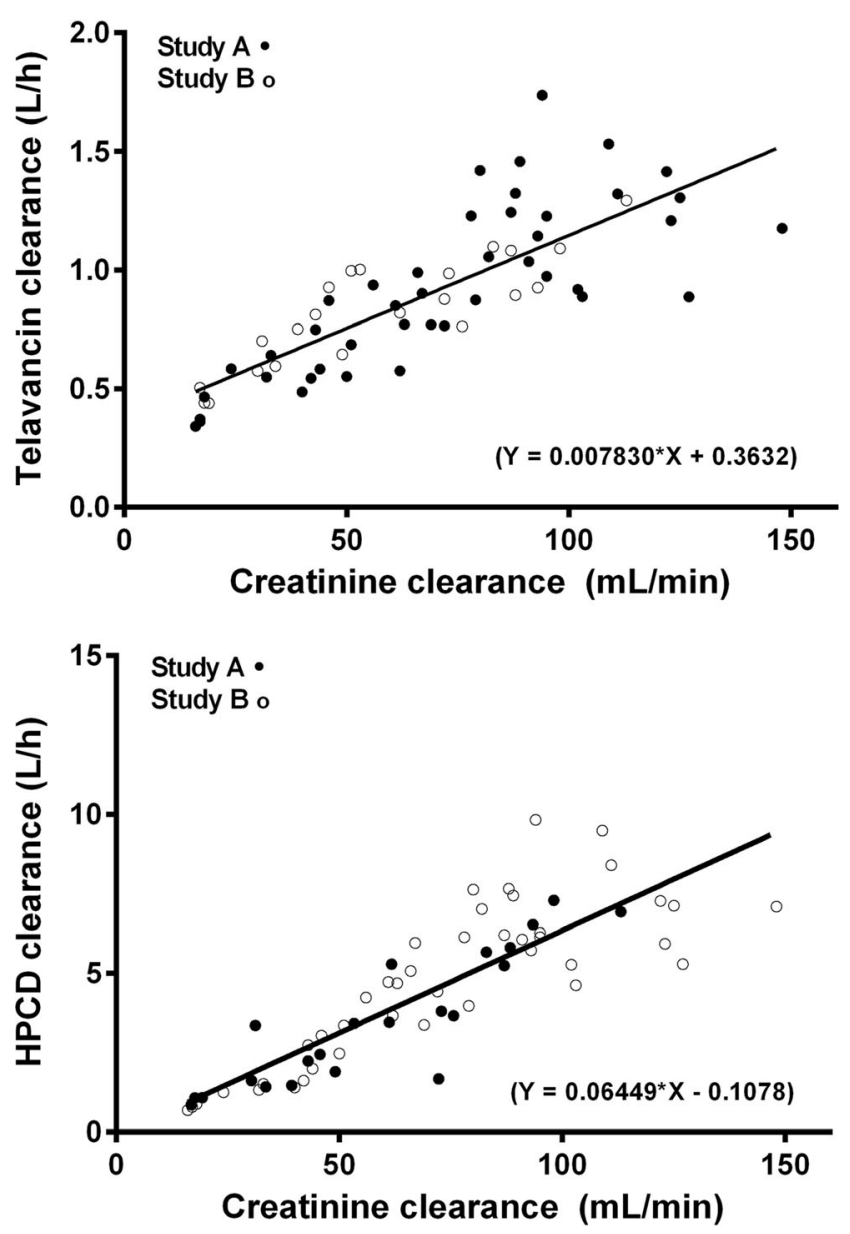

Fig. 2 Correlation plots of creatinine clearance versus $\mathbf{a}$ telavancin and $\mathbf{b}$ hydroxypropylbetadex total body clearance. $\mathrm{CL}_{\mathrm{cr}}$ was calculated using the Cockcroft-Gault equation without normalization for body surface area

\section{Safety and tolerability}

A single i.v. infusion of telavancin $7.5 \mathrm{mg} / \mathrm{kg}$ (study A) or $10 \mathrm{mg} / \mathrm{kg}$ (study B) was well tolerated in subjects with normal renal function as well as in those with varying degrees of renal impairment. Treatment-emergent adverse events (TEAEs) in study A and B, respectively, were reported by 17/29 (59\%) and $7 / 43(16.3 \%)$ of the subjects, including $5 / 6(83 \%)$ and $0 /$ $14(0 \%)$ with normal renal function, $4 / 7(57 \%)$ and $1 / 13$ (7.7 \%) with mild renal impairment, $3 / 6$ (50\%) and 2/8 (25\%) with moderate renal impairment and 3/4 (75\%) and 4/8 (50 \%) with severe impairment as well as 2/6 (33\%) subjects with ESRD (study A only). The most common TEAEs reported in study A were foamy urine $(n=6)$, dysgeusia $(n=5)$, nausea $(n=4)$, headache $(n=3)$, dizziness $(n=2)$, abdominal distension $(n=2)$ and somnolence $(n=2)$. One subject with mild renal impairment experienced flushing of the upper body (consistent with 'red man' syndrome), resulting in discontinuation of the infusion after two thirds of the dose had been administered. This subject was treated with i.v. chlorpheniramine and recovered fully.
No clinically significant changes in haematology, blood chemistry, urinalysis, vital signs, physical signs or electrocardiogram (ECG) were detected following telavancin administration. Similarly, no clinically significant abnormalities were detected in ten subjects with various degrees of renal impairment who underwent audiology assessments. In study B, the most frequently reported event was ECG QT prolongation as observed in three subjects $(7.0 \%)$, followed by increased blood lactate dehydrogenase in two subjects (4.7\%); these were mild and transient. Prolongation in ECG QT interval was reported in two subjects with severe renal impairment and one subject with moderate renal impairment; all cases were transient and reported as abnormal and clinically significant by the investigator. No serious adverse events were reported.

\section{Discussion}

There is an increase in AUC and $t_{1 / 2}$ for telavancin and a decrease in CL with increasing renal impairment, but no substantive change in maximum concentration after a single-dose administration. Additionally, the data suggest that, while the renal route is clearly important, other routes of elimination may also be involved.

In study B, urine was collected for $96 \mathrm{~h}$, which is more than sufficient for complete excretion, based on the estimates of $t_{1 / 2}$, even in severe renal impairment. Despite this, only $28 \%$ of the administered dose was recovered unchanged, suggesting that renal elimination of unchanged telavancin may not be the primary route of elimination in patients with moderate to severe renal impairment. Following i.v. administration, telavancin is largely excreted intact in urine (82\% after a single administration of $10 \mathrm{mg} / \mathrm{kg}$ ) [9], with the remaining dose being eliminated as several hydroxylated metabolites. In subjects with increasing renal impairment, the renal contribution to $\mathrm{CL}$ will be reduced in favour of the metabolic component, resulting in a reduced percentage of telavancin being recovered unchanged.

Based on previous data from subjects with normal renal function, the $t_{1 / 2}$ of hydroxypropylbetadex was $2.5 \pm 0.84 \mathrm{~h}$ (data on file) [15]. In previously studied patients with severe renal impairment, the $t_{1 / 2}$ of hydroxypropylbetadex was $15.6 \pm 6.0 \mathrm{~h}$, and total CL was $0.67 \pm 0.2 \mathrm{~mL} / \mathrm{h} / \mathrm{kg}$ (data on file, referenced in [15]), values that are consistent with the results of our study. There was no clear change in $V_{\text {ss }}$ of hydroxypropylbetadex with worsening renal function, although total body CL increased in proportion to decreases in eGFR, indicating that renal impairment reduces hydroxypropylbetadex CL, resulting in an increase in AUC. However, given the dosage adjustment in patients with moderate $\left(\mathrm{CL}_{\mathrm{cr}} 30-50 \mathrm{~mL} / \mathrm{min}\right)$ and severe (10-<30 $\mathrm{mL} / \mathrm{min})$ renal impairment, hydroxypropylbetadex exposure is expected to be reduced.

In study A, approximately $6 \%$ of the telavancin dose was eliminated during a 4-h haemodialysis session, but the 
calculated haemodialysis clearance is approximately $25 \%$ of total body CL. This observation suggests that a longer duration of dialysis might clear a larger proportion of drug dose.

Plasma concentrations of hydroxypropylbetadex were also higher in subjects with renal impairment in both studies as well as in haemodialysis patients (study A only). However, dialysis is known to remove hydroxypropylbetadex [15]. The differential effect of renal impairment on telavancin exposure versus hydroxypropylbetadex exposure may be due to a lack of metabolic clearance.

To conclude, dose adjustment of telavancin in patients with renal impairment is supported by the findings of two independent phase 1 studies in subjects with varying degrees of renal impairment. Telavancin $10 \mathrm{mg} / \mathrm{kg}$ every $24 \mathrm{~h}$ is recommended for patients with $\mathrm{CL}_{\mathrm{cr}}>50 \mathrm{~mL} / \mathrm{min}, 7.5 \mathrm{mg} / \mathrm{kg}$ every $24 \mathrm{~h}$ for patients with $\mathrm{CL}_{\mathrm{cr}} 30-50 \mathrm{~mL} / \mathrm{min}$ and $10 \mathrm{mg} / \mathrm{kg}$ every $48 \mathrm{~h}$ for those with $\mathrm{CL}_{\mathrm{cr}} 10-30 \mathrm{~mL} / \mathrm{min}$. Results from two independent phase 1 studies suggest that dose adjustment of telavancin is required in subjects with varying degrees of RI.

Acknowledgments The contributions of D. G. Wilbraham, Guy's Drug Research Unit, Quintiles Inc., London, UK; R. J. Noveck, MDS Pharma Services, New Orleans, LA, USA; M. R. Goldberg, M. M. Kitt and J.-P. Shaw, formerly of Theravance, Inc.; and W. Krauwinkel, Astellas Pharma Global Development, Inc., are gratefully acknowledged. The research and publication process was supported jointly by Theravance, Inc. and Astellas Scientific and Medical Affairs, Inc. Part of this work was presented at the 14th European Congress of Clinical Microbiology and Infectious Diseases, Prague, Czech Republic, May 1-4, 2004 [Poster P1028]. Writing and editorial support was provided by Gill Sperrin, a medical writer with Envision Scientific Solutions, and Emily Hutchinson and Ivo Stoilov formerly with Envision Scientific Solutions, funded jointly by Theravance, Inc. and Astellas Scientific and Medical Affairs, Inc.

Conflict of interest Dr. Barriere is an employee, and holds equity securities, of Theravance Biopharma US., Inc. Dr. Worboys is an employee of Theravance Biopharma US., Inc. Dr. Wong was an employee of Theravance, Inc., at the time of the studies.

Author contributions All authors meet the criteria for authorship as recommended by the International Committee of Medical Journal Editors (ICMJE), were fully responsible for all content and editorial decisions and were involved at all stages of manuscript development. S.L.B and S.L.W designed the study. P.W, S.L.W and S.L.B contributed to the analysis and interpretation of data, drafting and revision of manuscript and provided final approval for publication.

Open Access This article is distributed under the terms of the Creative Commons Attribution 4.0 International License (http:// creativecommons.org/licenses/by/4.0/), which permits unrestricted use, distribution, and reproduction in any medium, provided you give appropriate credit to the original author(s) and the source, provide a link to the Creative Commons license, and indicate if changes were made.

\section{References}

1. Krause KM, Renelli M, Difuntorum S, Wu TX, Debabov DV, Benton BM (2008) In vitro activity of telavancin against resistant gram-positive bacteria. Antimicrob Agents Chemother 52(7): 2647-2652

2. Higgins DL, Chang R, Debabov DV, Leung J, Wu T, Krause KM, Sandvik E, Hubbard JM, Kaniga K, Schmidt DE Jr, Gao Q, Cass RT, Karr DE, Benton BM, Humphrey PP (2005) Telavancin, a multifunctional lipoglycopeptide, disrupts both cell wall synthesis and cell membrane integrity in methicillin-resistant Staphylococcus aureus. Antimicrob Agents Chemother 49(3): 1127-1134

3. Lunde CS, Hartouni SR, Janc JW, Mammen M, Humphrey PP, Benton BM (2009) Telavancin disrupts the functional integrity of the bacterial membrane through targeted interaction with the cell wall precursor lipid II. Antimicrob Agents Chemother 53(8):33753383

4. Health Canada (2010) VIBATIV ${ }^{\circledR}$. Available at http://www.hc-sc. gc.ca/dhp-mps/alt_formats/pdf/prodpharma/sbd-smd/phase1decision/drugmed/sbd smd 2010 vibativ 107792-eng.pdf. Accessed 19 March $201 \overline{5}$

5. VIBATIV ${ }^{\circledR}$ [package insert] (2009). South San Francisco, CA: Theravance, Inc. Available at: http://www.vibativ.com. Accessed 19 March 2015

6. Clinigen Healthcare Ltd (2014) VIBATIV summary of product characteristics. Available at: http://www.ema.europa.eu/docs/en GB/document_library/EPAR_-_Product_Information/human/ 001240/WC500115364.pdf. Accessed 19 March 2015

7. Shaw JP, Seroogy J, Kaniga K, Higgins DL, Kitt M, Barriere S (2005) Pharmacokinetics, serum inhibitory and bactericidal activity, and safety of telavancin in healthy subjects. Antimicrob Agents Chemother 49(1): 195-201

8. Wong SL, Barriere SL, Kitt MM, Goldberg MR (2008) Multiple-dose pharmacokinetics of intravenous telavancin in healthy male and female subjects. J Antimicrob Chemother 62(4):780-783

9. Shaw JP, Cheong J, Goldberg MR, Kitt MM (2010) Mass balance and pharmacokinetics of [14C] telavancin following intravenous administration to healthy male volunteers. Antimicrob Agents Chemother 54(8):3365-3371

10. Goldberg MR, Wong SL, Shaw JP, Kitt MM, Barriere SL (2010) Single-dose pharmacokinetics and tolerability of telavancin in elderly men and women. Pharmacotherapy 30(8):806-811

11. Wong SL, Sorgel F, Kinzig M, Goldberg MR, Kitt MM, Barriere SL (2009) Lack of pharmacokinetic drug interactions following concomitant administration of telavancin with aztreonam or piperacillin/tazobactam in healthy participants. J Clin Pharmacol 49(7):816-823

12. Cockcroft DW, Gault MH (1976) Prediction of creatinine clearance from serum creatinine. Nephron 16(1):31-41

13. Levey AS, Bosch JP, Lewis JB, Greene T, Rogers N, Roth D (1999) A more accurate method to estimate glomerular filtration rate from serum creatinine: a new prediction equation. Modification of Diet in Renal Disease Study Group. Ann Intern Med 130(6):461-470

14. Tukey JW (1977) Exploratory data analysis. Addison-Wesley

15. Mohr JF, Finkel KW, Rex JH, Rodriguez JR, Leitz GJ, OstroskyZeichner L (2004) Pharmacokinetics of intravenous itraconazole in stable hemodialysis patients. Antimicrob Agents Chemother 48(8): $3151-3153$ 